\title{
Estudo Prévio 19 - Editorial
}

\author{
Filipa Ramalhete \\ framalhete@autonoma.pt \\ CEACT/UAL - Centro de Estudos de Arquitetura, Cidade e Território da Universidade Autónoma \\ de Lisboa e CICS.Nova - Centro Interdisciplinar de Ciências Sociais da Universidade Nova de \\ Lisboa \\ João Caria Lopes \\ joaocarialopes@gmail.com \\ CEACT/UAL - Centro de Estudos de Arquitetura, Cidade e Território da Universidade Autónoma \\ de Lisboa
}

Para citação: LOPES, João Caria; RAMALHETE, Filipa - Estudo Prévio 19 - Editorial. Estudo Prévio 19. Lisboa: CEACT/UAL - Centro de Estudos de Arquitetura, Cidade e Território da Universidade Autónoma de Lisboa, 2020, p.1. ISSN: 2182-4339 [Disponível em: www.estudoprevio.net]. https://doi.org/10.26619/2182-4339/19ED

Creative Commons, licence CC BY-4.0: https://creativecommons.org/licenses/by/4.0/

A publicação do número DEZANOVE da revista EP - Estudo Prévio retoma, ainda em contexto pandémico, uma tradição que tem sido uma constante na revista, os dossiers temáticos. Neste número convidámos o arquiteto Paulo Moreira, doutorado em Arquitetura, com investigação sobre a Cidade Informal, no contexto europeu e africano, que organizou um dossier que inicia com uma entrevista biográfica à arquiteta e urbanista Isabel Raposo e nos apresenta depois perspetivas de investigação em contextos territoriais distintos, Angola e Cabo Verde, terminando com uma recensão sobre um marcante livro sobre a realidade da favela brasileira. Como é habitual, a revista inclui, em texto e em áudio, uma entrevista a um arquiteto, desta vez ao escultor e professor Carlos Nogueira, uma entrevista que publicamos com especial prazer, uma vez que o professor Carlos Nogueira foi, durante muitos anos, professor no $1^{\circ}$ ano do curso de Arquitetura da Autónoma, tendo contribuído de forma inolvidável - com as suas aulas repletas de arte e poesia - para a formação de centenas de arquitetos que passaram pela nossa escola. 